\title{
An Investigation using a Case Study Approach into the Impact on a Counselling Team in the UK of an Organisational Restructuring within a Family Support Service
}

\section{(c) 2016 Gillian Robinson}

\begin{abstract}
Following an organisational restructuring of a hospice in the UK, the author has used a case study approach to investigate the impact of this on a team of volunteer counsellors of which she was a member. A small number of the volunteer counsellors completed a questionnaire and some managers and other professionals were interviewed, and summaries of responses through each method are presented. The results are reviewed in terms of several transactional analysis concepts, and the author concludes by hypothesising that the impact of the restructuring on the counsellors appeared to parallel the sense of vulnerability felt by their clients.
\end{abstract}

\section{Key words}

hospice, transactional analysis, psychological distance, psychological games, discounting, group imago, case study

\section{Introduction}

This investigation was undertaken within a hospice in the UK where an organisational restructuring had drawn together three areas of service user support which had worked in informal collaboration in the past: Chaplaincy, Bereavement Services and Admissions/Discharge. The all-encompassing department became Family Support Services, led by a Family Support Services Manager under the guidance of the Director for Patient Services.

The research focuses on the impact of the changes on the team of volunteer counsellors, of which the author was one. Prior to the restructuring, the counsellors had been led by a Bereavement Services Manager, who had been in post for more than six years; he was also a professional counsellor, so had extensive knowledge of counsellors' professional, ethical, training and support needs.

\section{Literature Review}

\section{The Hospice Movement}

The model of the modern hospice movement in the UK and internationally was inspired by the work of Dame Cicely Saunders, whose vision was to move away from being sanctuaries run by religious orders for the dying poor and instead to emphasise palliative care. Dame Saunders "... devoted her life to making sure people could die with dignity and free from pain." (Richmond, 2005).

The hospice where this research was undertaken was established in 1992 and the following are references to some of the reports which influenced the restructuring.

Building on the Best (Department of Health 2003) concerned the UK Government pledge to give patients real choice rather than theoretical: in other words, choice would be made available through equality of access not only to those able to navigate the complex system but "we want choice, information and the power of personal preference extended to the many" (p. 3). The main challenges and changes were seen to be to give people a bigger say, particularly about the right to die where the individual wished, the right to die with dignity in one's own home, an increased choice of access to a wider range of services in primary care, and for individuals to have more information about the progress of their treatment and care. The report stated "Real change will happen at the front line, with support from the centre, fuelled by encouragement and expectation from patients and drawing on the experience of partner organisations and other experts." (p. 55)

This was followed by a NICE (National Institute for Clinical Excellence) (2004) report on supportive and palliative care for adults with cancer, in which it was 
highlighted that "... patients want to be treated as individuals, with dignity and respect, and to have their voices heard in decisions about treatment and care." ( $p$. 3). Through a National Cancer Patient Survey, it had been identified that there were geographic variations in the delivery of service so a service model was defined that emphasised assessing the need of the patient at the specific time in treatment, and recognition that some would need additional support. It was recommended that information regarding the availability of support should be made available to families and carers quite separately from information regarding the patient's treatment and care.

In a House of Commons Health Committee report (2004) it stated that, whereas $56 \%$ of people died in hospital, $20 \%$ at home, $20 \%$ in nursing or residential homes and $4 \%$ in hospitals, research indicated that the majority would choose to die at home. There was, however, an implication about the quality of care required by the dying and it was stated that "The right to a "good death" should be fundamental." (p. 38). More recently, Hughes-Hallett, Craft \& Davies (2011) acknowledged that, whilst "We want to ensure everyone is able to live well until they die ...the current system is confusing and does not help people get the care and support they need, or provide them with meaningful choice" (p. 6).

Throughout the literature, there were consistent themes: to hear patients and put their wants and needs at the centre; to provide clarity and ease of use, so patients can make informed decisions; to ensure that families and carers are offered timely, appropriate support and information over and above that which is provided for patients, and that support continues in bereavement when necessary. To achieve these aims, there is acknowledgement throughout of the need for transparency, effective communication, engagement and involvement at all levels (including patients) and clarity of vision. The restructuring at the hospice had been undertaken in line with these themes, although it will be seen below that some of the fundamentals had been overlooked when it came to the service providers, including clarity of vision, effective communication, engagement and involvement.

\section{Transactional analysis}

Transactional analysis concepts that appeared to be particularly relevant to the research in question included the three-cornered contract by English (1975), for which she highlighted the importance of clarity in the agreement between the organisation and other parties, and its development into psychological distancing by Micholt (1992). Micholt defines psychological distance as "a subjective measure, of sociometric origin, as experienced by each person." (p. 228) and comments that "[when] the distance between the three parties is perceived as equal. The contracts and expectations are clear on all sides, and there are clear role definitions for everyone. This is the ideal situation, in that it implies that all partners are open, willing to collaborate, and have no hidden agendas, certainly a worthy goal." (p.229). She also points out that sometimes "the facilitator identifies with the participants (and not with the Great Powers), who are from similar social, cultural or professional backgrounds." (p. 231) and explains that with this particular imbalance may be demonstrated by We're OK, They're not OK or We're not OK, They're not OK behaviours.

Micholt also suggests that "... one of the consequences [of lack of balanced psychological distances] is the occurrence of games." (p.231). Hence, Karpman's (1968) drama triangle was also likely to be useful in understanding how the roles of Persecutor, Rescuer and Victim might be being played out within the team and their management. Micholt suggests that this can be avoided "... by working with participants and the Great Powers on role definitions, problem definitions and mutual expectations (group imago exercises, identifying Parent or Child projections). This might include teaching parties how to negotiate with one another." (p. 233) As an extension of this, Summerton (1992) provides the game pentagon, which he describes as a model that "... was based on a systems approach to the relationship knots that occur in organisations so that players could begin to recognize their part in the whole event without feeling accused of playing psychological games." (p.67). This emphasis by Summerton on the roles having both “... negative and positive connotations [so that] groups such as families can enjoy playing these roles while analysing many handy games..." (p.74) meant that it was likely to become a useful model to use for this study.

The concept of discounting was also likely to be relevant, including Schiff \& Contributors' (1975) levels of T2: significance of stimulus, existence of problem and T3: possibility to change the stimulus, significance of problem, existence of options. Similarly, Berne's (1963) concept of the group imago as "The private structure, that is, the group as seen through the eyes of each member, in the group imago of the member. This private structure is the most decisive structural aspect for the outcome of the individual's therapy." (p. 153) can readily be converted from a therapeutic perspective to that of an organisational group. Clarkson (1991) went on to suggest that at a time of change, a group "... will usually regress to an earlier and less developed level of functioning and the group supervisor may need to help the group recycle through the various phases again." ( $p$. 38). Because the group leader in this study had previously been the team's line manager, it was possible that this might occur and would be an unhealthy position for him to be drawn into; of relevance is Clarkson's suggestion that "Leaders cannot responsibly avoid being leaders if that is the psychological need of the group in its initial phase, just as parents cannot abdicate all structuring and decision-making to an infant without endangering it." (p. 40). There was, therefore, a danger that the counsellors might believe that one person was their manager, but would go elsewhere for guidance. 


\section{Objectives/hypotheses}

This study began as an open investigation to explore the impact of an organisational restructuring on a team of volunteer counsellors. As such, there was no formal research question beyond an exploration.

As a result of the information obtained via questionnaires and interviews, a concluding hypothesis is that the outcomes of the organisational restructuring have paralleled in some way the dynamics experienced by the clients of the hospice.

This is a small case study only so the outcome can only be regarded as tentative, but the methodology might usefully be copied to investigate similar organisational changes were the results might parallel client dynamics.

\section{Methodology}

This research was conducted as a naturalistic study with a convenience sample. This method was chosen because the investigation was to be conducted within one organisational setting and with a limited number of participants, so that case study methodology seemed most appropriate. Widdowson (2011) has written extensively about case study research in line with McLeod's (2010) recommendations for this within counselling and psychotherapy, but the particular style applied by Widdowson refers to individual client cases so was not directly appropriate.

Hyett, Kenny \& Dickson-Swift (2014) comment usefully, after this research had been conducted, that case study research is increasingly popular but differences in the ways in which such research is being conducted make it difficult to define it as a consistent methodology. They propose that it should be "an investigation and analysis of a single or collective case, intended to capture complexity of the object of study" (\#2). They reviewed 34 case studies against a checklist of criteria relating to the quality of the work which they had based on material by Stake (1995), Merriam (2009) and Creswell (2013). They commented particularly on: how a focus on outcomes often resulted in a case study report rather than a case study; how they found case studies in the health and social science categories without any explicit argument for why a case had been selected and a lack of attention to the limitations of a convenience sample; how adequate contextual description is required to understand the setting or context; and the way in which researcher and case interactions are a defining feature of case study methodology.

The case study reported here avoids the risk of being focused on outcomes; it is a convenience sample selected because the researcher was already there so the limitations of this are addressed below; it has been possible to provide the contextual description; and it has also been possible to comment on the role and position of the researcher, although the lack of triangulation is also addressed below as a limitation.

\section{Ethical Considerations}

The research was done as part of studies towards a degree in Humanistic Transactional Analysis Counselling, with permission from the Hospice Management and approval from the Academic Ethics Committee of the University to carry out the research.

A Questionnaire Consent Proforma was used that included the comment that the results would be confidential and that participant anonymity would be preserved at all times. It also advised them that they had the right to withdraw from the survey at a later date, and asked them to sign that they gave their written permission for their responses to be used anonymously within the research. Similar statements appeared on the Interview Consent Proforma.

Employing questionnaires with a separate consent form offered participants a degree of anonymity; this felt appropriate as there was a sense of uncertainty and anxiety around the team at that time. It was this level of scare which led to a redesign of the questionnaire and an offer for completion on a second occasion, as will be explained below.

Organisation, participants and researcher

As stated above, the hospice in which this research took place was established in 1992 and had recently been restructured. It is a registered charity offering free care for patients with life limiting illness and support to their families and carers. It has over 750 volunteers in addition to around 110 employees. There are currently 11 volunteer counsellors, down from 18 in 2011, one of the team had died in 2012 and some had left at the time of the resignation of the former Bereavement Services Manager, perhaps also prompted by the restructuring.

Two of the volunteer counsellors completed Version 1 of the questionnaire and seven completed Version 2. Of those seven, two were qualified and five were trainees. One had 18 months service, four had 2 years' and 2 had 5 years' service in the hospice. Two were male and 5 were female, and their ages ranged fairly evenly from 35 to 65 years.

Semi--structured interviews were conducted by the researcher/author with the Family Support Service Manager (18 years service), the Administrator (2.5 years service), the Counselling Psychologist (3 months service) and the Supervisor of the counsellors (11 months service). Questions were emailed to the Volunteer Services Manage (12 years service).

As researcher/author, I comment here also on myself as researcher because I am one of the volunteer counsellors at the hospice. The restructuring has impacted me personally and I have first-hand experience of the impact on others, as I have witnessed it. Throughout the research I have sought to remain aware of my own biases and prejudices. As I have reflected and been reflexive during the process, I have aimed to 
present a balanced and ethical piece of research. Where I am aware of my biases and prejudices. I have owned the view to minimise the impact on this research paper.

\section{Questionnaires}

The content of the final questionnaire can be seen in Table 1.

The participant group was not large enough to produce meaningful quantitative data so this research has been conducted using a qualitative approach. The first questionnaire used consisted of a series of questions, some of which could be answered by factual information, but others which required opinions, e.g. What is your understanding of the progress of the changes?

Only two of the 11 participants invited submitted a completed questionnaire and it seemed that the anxiety and tension observed during team meetings might be linked to this lack of response. A second version was therefore designed, in which were provided a range of strongly agree to strongly disagree responses to statements that closely resembled the questions of the original questionnaire.

Seven completed Version 2 questionnaires were received, which was disappointing as informal conversations and small group discussions had indicated that the counsellors had strong feelings about the changes and the lack of understanding of the needs of the counsellors working in this setting.

However, 7 questionnaires represents $67 \%$ of the team, and analysis of some of the questions within it demonstrated that it covered a mix of length of experience, whether qualified or in training, and experience of the organisation prior, since and during the restructuring. The second version was handed out during a meeting and the rate of response may well have been affected by the Director of Patient Services offering support for the research at that meeting.

\section{Interviews}

Semi-structured interviews were used so that each interviewee was asked the same questions, and in order to be able to summarise responses and hopefully identify themes. The interviews were recorded and transcribed Participants were questioned about:

- their understanding of the rationale for the restructuring;

- $\quad$ their views on the impact for various groups e.g. service users, volunteer counsellors, employees;

- the anticipated 'life span' of a volunteer and of a volunteer counsellor;

- their opinion about the style of the organisation, for which they were invited to choose from Hierarchical, Parental, Consultative, Participative, Persuasive, Democratic, Autocratic or Chaotic;
- their personal experience of the restructuring, including anything they might have done differently with hindsight, and what further changes they believed necessary.

\section{Results}

\section{Questionnaire Results}

The responses to the Version 2 questionnaires are shown in Table 1. A final question was asked about how long participants planned to continue as volunteer counsellors within the hospice: two said they were considering leaving within the year and five said they had no plans to leave.

It is clear from the responses that the counsellors did not feel there had been clear communication of the rationale for the transition from being a bereavement service to being part of the Family Support Service. However, they did feel that they had had the opportunity to offer their opinions and give feedback, and that they had been heard because although their opinions were not sought prior to restructuring, their concerns and professional needs (supervision and training) were heard and acted on after the restructuring.

The consensus was that the transition had an impact on the counsellors, although not on their clients. This statements around the understanding of the role of the counsellors being understood by the organisation and management were evenly divided and this might have been impacted by individual counsellor's abilities to express their needs to others.

The feedback was unanimous about the supervisor understanding the counsellor's role, which is hardly surprising as the supervisor was a professional counsellor and a member of the same professional body as the team members. Although the team were split on a sense of belonging to the volunteer team at the hospice, they appeared to indicate a strong sense of identity as a team of counsellors. They recognised generally that their manager is the Family Support Service Manager (although one agreed yet wrote on the form that they did not know who their manager was), but said they would contact the Counselling Supervisor for guidance and support. This Supervisor is there for this when it is of a clinical nature, but it seems there is a lack of clarity around operational support.

There was a clear message from the counsellors that they did not feel supported prior to the changes; the opportunity had been missed to share the rationale and reporting mechanism with the team in advance of the restructuring.

\section{Interview Results}

The responses during the semi-structured interviews are summarised in Table 2. There was a general view that the restructuring was aimed at consolidating the services offered to patients, families and carers. It was suggested that the Bereavement Service had been operating in 


\begin{tabular}{|c|c|c|c|c|}
\hline Question & $\begin{array}{l}\text { Strongly } \\
\text { Disagree }\end{array}$ & Disagree & Agree & $\begin{array}{l}\text { Strongly } \\
\text { Agree }\end{array}$ \\
\hline Rationale for restructuring clearly communicated & 4 & 2 & 1 & \\
\hline Restructuring had an impact on me & & 1 & 5 & 1 \\
\hline Restructuring had an impact on my client & & 6 & 1 & \\
\hline I feel my role as counsellor is understood by the organisation & & 4 & 3 & \\
\hline I feel my role as counsellor is understood by the Management & & 3 & 4 & \\
\hline I feel my role as counsellor is understood by the Supervisor & & & 3 & 4 \\
\hline I feel my role as counsellor is understood by the the other counsellors & & 1 & 1 & 5 \\
\hline I feel I belong to the volunteer team & & 4 & 3 & \\
\hline I feel I belong to the counselling team & & 1 & 6 & \\
\hline The Family Support Service Manager is line manager of the counsellors (1 don't know) & & & 6 & \\
\hline For guidance I would contact the Family Support Service Manager & & 4 & 2 & 1 \\
\hline For guidance I would contact the Counselling Supervisor & 1 & 6 & & \\
\hline I have had the opportunity to offer my opinion and/or feedback & & 1 & 6 & \\
\hline I feel that feedback from volunteer counsellors has been heard & & 2 & 5 & \\
\hline I felt supported and cared for prior to the changes by the organisation & 2 & 3 & 2 & \\
\hline I felt supported and cared for prior to the changes by the Management & 2 & 3 & 1 & \\
\hline I felt supported and cared for prior to the changes by the Supervisor & 1 & 3 & 1 & 2 \\
\hline I felt supported and cared for prior to the changes by the other Counsellors & & 1 & 5 & 1 \\
\hline I feel supported and cared for now by the organisation & & 4 & 3 & \\
\hline I feel supported and cared for now by the Management & & 3 & 4 & \\
\hline I feel supported and cared for now by the Supervisor & & & 7 & \\
\hline I feel supported and cared for now by the other counsellors & & & 7 & \\
\hline
\end{tabular}

Table 1: Questionnaire Responses 


\begin{tabular}{|c|c|}
\hline Questions & Summary of Responses \\
\hline $\begin{array}{l}\text { Understanding of the rationale for the } \\
\text { restructuring }\end{array}$ & $\begin{array}{l}\text { Several comments about bringing the service back into the organisation, avoiding isolation, } \\
\text { using skills and expertise more for clients. } \\
1 \text { comment of "not privy to the rationale" }\end{array}$ \\
\hline Impact on service users & 2 comments on better quality of service; others said no impact \\
\hline Impact on volunteer counsellors & $\begin{array}{l}\text { Comments about not being looked after, left in a vulnerable place with no structure, hearsay, } \\
\text { unease and anxiety, lack of clarity and a stressful vacuum; also that some had used the } \\
\text { change as a vehicle for moving on }\end{array}$ \\
\hline Impact on volunteer services & 2 commented on confusion about who is who but others said little or no impact \\
\hline Impact on employees & $\begin{array}{l}\text { Huge learning curve, no handover, chaotic, lack of clarity; } 1 \text { said no effect as those joining are } \\
\text { new positions }\end{array}$ \\
\hline Anticipated 'life span' of a volunteer & All seem to stay a long time; there is a waiting list \\
\hline $\begin{array}{l}\text { Anticipated 'lifespan.' of a volunteer } \\
\text { counsellor }\end{array}$ & $\begin{array}{l}\text { Counsellors stay a long time, five years could be average, counsellors come on placement and } \\
\text { stay when qualified }\end{array}$ \\
\hline Style of organisation & 3 said Hierarchical, also autocratic, chaotic \\
\hline $\begin{array}{l}\text { In hindsight, is there anything you would } \\
\text { have done differently }\end{array}$ & $\begin{array}{l}\text { Thought through transition beforehand, more transparency to limit anxiety, more participation } \\
\text { and communication, and understanding of counselling and counsellor needs }\end{array}$ \\
\hline Further changes needed & $\begin{array}{l}\text { Several comments about availability and continuity of supervision, also recognition and } \\
\text { acknowledgement of efforts made }\end{array}$ \\
\hline
\end{tabular}

Table 2: Interview Responses

isolation and that the umbrella of Family Support Service would mean that service users had one starting place where their needs can be assessed and directed to appropriate experts. It was viewed that this would bring the hospice structure in line with that operated in other hospices, and also that services could then be monitored, managed and benchmarked more effectively.

\section{Discussion}

Contracting and Psychological Distances

Combining English's (1975) contracting ideas with Micholt's (1992) concept enables us to see that the contract was changed significantly and led to problems of psychological distance. Using a simple three-cornered contract, the parties of organisation, counsellor and Bereavement Services Manager had the latter changed to the Family Support Services Manager. Hence what might well have been a shortened psychological distance between the original manager and the counsellors risked becoming an elongated psychological distance between the counsellors and the new manager. In addition, it seems that the Clinical Supervisor now became another party to the contract, raising the likelihood that there would again be a shortened psychological distance between them and the counsellors which would reinforce the sense that there was an elongated psychological distance between counsellors and new manager. The general lack of information and consultation also meant that it was extremely likely that the counsellors would feel at a considerable psychological distance from the organisation itself.

Psychological Games

In terms of Karpman's (1968) drama triangle, the Management may be thought of as in the role of Persecutor and the Supervisor and Counsellor as being the Victim. The team of counsellors are stuck in this place and have been there since March 2012 when the Bereavement Services Manager left his post, and possibly even from the time he resigned (October 2011) and began to prepare to leave. Although the restructuring would inevitably bring the group back to these initial uncertain stages of group development it was still there a year later. This is unhealthy for the continuing success of the team and its membership. To move forward and eliminate the risks at both clinical and operational levels there need to be interventions to bring the contract back into a place of balance through clarity of vision and responsibilities.

Summerton's (1992) game pentagon has been useful when considering what might have been happening, is happening and could happen with the restructuring. It offers reflexivity to the organisational changes and I have in this instance considered from my biases as a team member, researcher and from the information I have gathered through the questionnaires and interviews. As with the drama triangle, which is a study of the individual's interpersonal transactions, the roles change as the transactions between those involved happen. The game pentagon is 
therefore a study of the social interactions of the members of the group. However, the roles can be construed as furthering or hindering those involved and the organisation of which they are in the service. From the information gathered in this work I have considered the roles that have emerged prior to the restructuring, as it happened and now.

Back then, the Director of Patient Services was in the role of Stage Manager, the counsellors, Family Services Manager and Volunteer Service Manager were the Spectators. Those who had decided to leave or held positions that were redundant had a feel of shifting between Saviour, Scapegoat and Sniper depending whose view was being canvassed and how safe that person was feeling at the time.

As the changes became reality, Director of Patient Services continued in the role of Stage Manager, the counsellors' uncertainties and anxieties moved them towards being the Sniper as they began to offer their opinions, formally and informally. The Family Service Manager and Social Worker became Scapegoats and the former Bereavement Services Manager, now the counsellors' clinical supervisor, became the Saviour. However, as the responsibilities of his role had altered considerably and he could no longer offer the leadership he had previously, there remained the gap of who was the team's operational leader. As this continued and transactions have gone back and forth, the supervisor has been at risk of being cast in the role of Scapegoat and/or Sniper. However he has offered the counsellors clarity about his role and what he can and cannot offer the team.

18 months after the team's all-encompassing leader left, the team and service continue to function and the team has shrunk. The Director of Patient Services has left and the role of Stage Manager seems vacant. The communication is improved and is two way. There are plans being formed for recruitment, training and induction of additional qualified counsellors to boost the team's number. The Family Services Manager is acting Director Patient Services. The Clinical Psychologist and Social Worker are in situ and communicating with the counsellors. The team's clinical needs are taken care of as the supervisor's contract is more permanent. Procedures are emerging regarding length of work and assessment of client needs. However there are still gaps procedurally and responsibilities are not defined, nor is the direction of the counselling team's future within the family services. There is an opportunity for an individual or individuals to offer clarity of vision and a plan for addressing the gaps. As identified by Clarkson (1991) "The process by which the provisional group imago is changed is influenced by member's characteristics, but also by the leadership tasks and behaviours" (p. 39)

\section{Discounting}

The possible existence of discounting at T2 and T3 (Schiff \& Contributors 1975) was evidenced in the views of the counsellors, where they felt that the rationale for change was not clearly communicated. This view is further supported by the group interviews - for instance in one interview the comment was made that there was 'a huge kind of vacuum and what people will do with that is try and fill the vacuum with what is going on and there has not really been any answers so that has been kind of stressful for people'.

\section{Group imago}

When considering the group imago in line with Berne's (1963) stages, we can look at the possibility of what may be happening rather than showing a particular individual's imago. When considering the distancing in terms of group imago, the provisional imago is usually the individual's first 'experience' of the group, holding the fantasy of how the group will be. In general this would be established before the initial meeting as a group. Self and the organisation are identified and the other members indicated by the undifferentiated slot, which in this case includes the supervisor. In the scenario at the hospice it is unusual to find a developed team back at this initial stage; however the restructure caused the group to return to this early developmental stage. Clarkson (1991) suggested that a group may regress and need the leader to help the group, but I perceive the supervisor as being with the counsellors in this 'general' imago, albeit in an altered role. Being seen as undifferentiated from the counsellors is an unhealthy position for him to be drawn into and I believe creates further distancing from the organisation. It may be that this lack of differentiated state is as a result of the groups needs but this will remain a risk for the team, organisation, management and supervisor while roles and responsibilities remain undefined; it appears that the decision on to whom to turn for guidance and support is being left to the counsellors' discretion. As Clarkson (1991) commented "Bad management of critical periods in a group's life may affect its future functioning just as ineffective parenting affects an individual's subsequent social and psychological development".(p.37)

Also commenting on the provisional stage, Berne (1963) said; "In this stage the leader's most important task is to deal with external group process and to define the major external and internal boundaries" (p. 55). The group has deficient internal boundaries with roles and responsibilities undefined, with the organisation and management excluded, suggesting the team and supervisor function in isolation.

\section{Limitations}

An obvious limitation has been the numbers involved in this study; however it is hoped that it will demonstrate a way of investigating the impact of a restructuring within a relatively small organisation, and particularly of the usefulness of TA concepts in such an activity.

Another limitation, already mentioned, was that the researcher was also a member of the team being researched, and had experienced personally the events being investigated. This was mitigated to some extent by the fact that this study was completed under professional 
supervision and was also reviewed by various members of the tutor team and assessors at the University where the author was undertaking her studies.

The convenience sample of organisation and participants was selected because the researcher was already there and needed to conduct research as part of her studies; this could be seen as a limitation in that it was done to produce an assignment rather than because the management of the organisation had requested any consultancy support. This has meant, in turn, that it may be seen as research for the sake of research, in that the events being investigated have already occurred and the findings cannot, therefore, influence what happens next in the short term. However, it is to be hoped that publication may lead to more attention being paid to the potential difficulties in any future restructurings within the hospice movement or indeed within the Health Service generally.

\section{Conclusion}

This work has been a consideration of the impact for volunteer counsellors at a hospice as a result of restructuring. As I began the study, I believed that I would find there had been little impact. I believed that the counsellors and I were displaying a resistance to change. However, as I gathered information and opinions over the months, and as the restructuring continues to develop, I believe that my own view discounted the significance of the impact on the counsellors, staff, service users and patients.

From the literature review, the rationale for the restructuring becomes clearer. The Family Support Service would offer patients, families and carers an allencompassing service, which in turn could be benchmarked and monitored against other hospices for funding and also compliance with government directives and policies. It also provided an opportunity for the skills of counsellors to be used more fully, with earlier intervention where appropriate.

However, the restructuring caused anxiety and uncertainty for the counsellors. They did not know what the future for the service was going to be or how they were to fit into the new structure. They no longer had their line manager and were therefore concerned about potential lack of understanding of and provision for their professional requirements such as clinical supervision and training.

I have been impacted by the parallel of the team's position in the hospice and that of the hospice within our society - both appear to be hidden. The existence and purposes are known, but it is not until the service, or a counsellor, is required, that the services provided are fully understood, valued and appreciated. The counsellors have been left in a vulnerable position without the operational support that they had previously; this is another parallel with the work they do with the bereft who are in a vulnerable place due to loss.
Gillian Robinson BA Hons Transactional Analysis Humanistic Counselling, is an Accredited Member of the British Association for Counselling and Psychotherapy, and can be contacted on contact@gillianrobinsoncounselling.co.uk

\section{References}

Berne, E (1963) Structure and Dynamics of Organizations and Groups Philadelphia: Lippincott

Clarkson, P. (1991) Group Imago and the Stages of Group Development Transactional Analysis Journal 21 (1):36-50.

Creswell, J W (2013) Qualitative inquiry and research design: Choosing among five approaches ( $3^{\text {rd }}$ ed) Thousand Oaks, CA: Sage

Department of Health. (2003) Building on the Best' http://www.official-

documents.gov.uk/document/cm60/6079/6079 Accessed: 31 January 2013

English, F. (1975) The Three-Cornered Contract Transactional Analysis Journal 5(4):383-384

House of Commons Health Committee (2004) Palliative Care http://www.publications.parliament.uk/pa/cm200304/cmselect/c mhealth/454/45403 Accessed: 31 January 2013

Hughes-Hallett, T, Craft, Alan \& Davies, Catherine. (2011)'Palliative Care Funding Review: Final Report: Funding the Right Care and Support for Everyone'. http://palliativecarefunding.org.uk/PCFRFinal Report Accessed: 31 January 201

Hyett, N, Kenny, A \& Dickson-Swift, V (2014) Methodology for method? A critical review of qualitative case study reports International Journal of Qualitative Studies on Health and Wellbeing 9: 23606 - http://dx.doi.org/10.3402/qhw.v9.23606

Karpman, S. (1968) Fairy Tales and Script Drama Analysis Transactional Analysis Journal 9(26):39-43

McLeod, John (2010) Case Study Research London: Sage Publications

Merriam, S B (2009) Qualitative research: A guide to design and implementation ( $3^{\text {rd }}$ ed) San Francisco: Jossey-Bass

Micholt, N. (1992) Psychological Distance and Group Intervention Transactional Analysis Journal 22(4):228-233.

National Institute for Clinical Excellence (2004) 'Improving Supportive and Palliative Care for Adults with Cancer http://www.nice.org.uk/nicemedia/live/10893/28816/28816 Accessed: 31 January 2013

Richmond, Caroline (2005) Dame Cicely Saunders http://www.ncbi.nlm.nih.gov/pmc/articles/PMC1179787/ accessed 19 June 2013

Schiff, J \& Contributors (1975) Cathexis Reader: Transactional Analysis Treatment of Psychosis, New York: Harper \& Row Publishers Inc

Stake, R E (1995) The art of case study research Thousand Oaks, CA: Sage

Summerton, O. (1992) The Game Pentagon Transactional Analysis Journal 22(2):66-75

Widdowson, Mark (2011) Case Study Methodology International Journal of Transactional Analysis Research, 2:1 25-34 